\title{
Sustainable product development strategies: business planning and performance implications
}

Rebecca De Coster and Richard J Bateman

School of Engineering and Design, Brunel University, UK

\begin{abstract}
Manufacturing firms are under many financial and competitive pressures which focus attention on the performance of their manufacturing processes. In this paper the opportunities for improving the environmental impact of products within the constraints of existing manufacturing infrastructure are examined. Approaches which support sustainability in two aspects are proposed, firstly, the provision of products to the users in ways which extend the product life and secondly, manufacturing approaches which reduce resource usage. This paper outlines three different sustainable development strategies for different product types and describes the cost implications for manufacturers across the lifecycle. The performance measures affected by these strategies are examined drawing on product development case studies from a number of high technology sectors to highlight the different approaches taken. The results are intended to aid manufacturers during the earliest stages of business planning to consider alternative product development approaches which are more sustainable.
\end{abstract}

\section{Keywords}

sustainable design strategies, life cycle analysis, business planning 


\section{INTRODUCTION}

Our focus in this paper is on identifying strategies which will assist manufacturers to achieve 'sustainable product development' which according to Van Weenen [1] has a wider scope than reducing materials and other resources in the product design. For the purposes of this research it is recognised that many manufacturing firms have invested in existing infrastructure and have well established practices to enable them to compete in a highly demanding environment.

Various parties have identified the drivers and challenges of sustainability and proposals for sustainability management have been published such as the standards ISO 14001 (as discussed by Donnelly, [2]). Previous research and manufacturing firms have made efforts to improve the sustainability of their products which range from reducing materials used in products (as Ljungberg [3]) to self-sustaining energy management systems highlighted by Mann and Jones [4]. Similarly, firms have been encouraged to assess their key operations and working practices to make improvements to power requirements; energy usage and handling of waste and reducing the levels of these items.

Given all the above efforts by governmental and industrial firms and organisations it still seems that the manufacturing sector needs to do more in terms of sustainable manufacturing. This is currently limited in its achievements due to the business model currently in use which is focused around product creation (and hence sales) by the manufacturers rather than the more holistic view of the life-cycle. The current mode of operation is that product usage by users consists of purchasing an item and then using it 
until such a point where it typically is replaced. From the users perspective the replacement decision is based on a number of situational influences (such as wear and tear) which lead to a comparison between the actual condition of the currently owner product and the new purchase as realised by van Nes and Cramer [5].

A move towards more sustainable product strategies requires that manufacturers consider the overall life-cycle and not be restricted in scope to the creation of the product argues Schmidt and Butt [6] but also the user stages and end stage as shown in Figure 1. Instead the approach being proposed in this paper has a broader remit i.e. that of 'sustainable product development' which according to Van Weenen [1] has a wider scope than reducing materials and other resources in the product design. The elements of the sustainable development strategies for manufacturing firms comprise firstly, product provision and secondly manufacturing process configuration as shown in Figure 1.

As technology continues to advance and more advanced and integrated solutions are developed then there is the risk that the more advanced equipment becomes harder to disassemble and handle for EoL (End of Life) processing. Further, hardware based systems are increasingly integrated by vendors who are seeking high performance products that will fare well in a competitive market, however, this performance may require higher integration of components and systems which require and use more energy both during the production stage and during the product lifetime. 


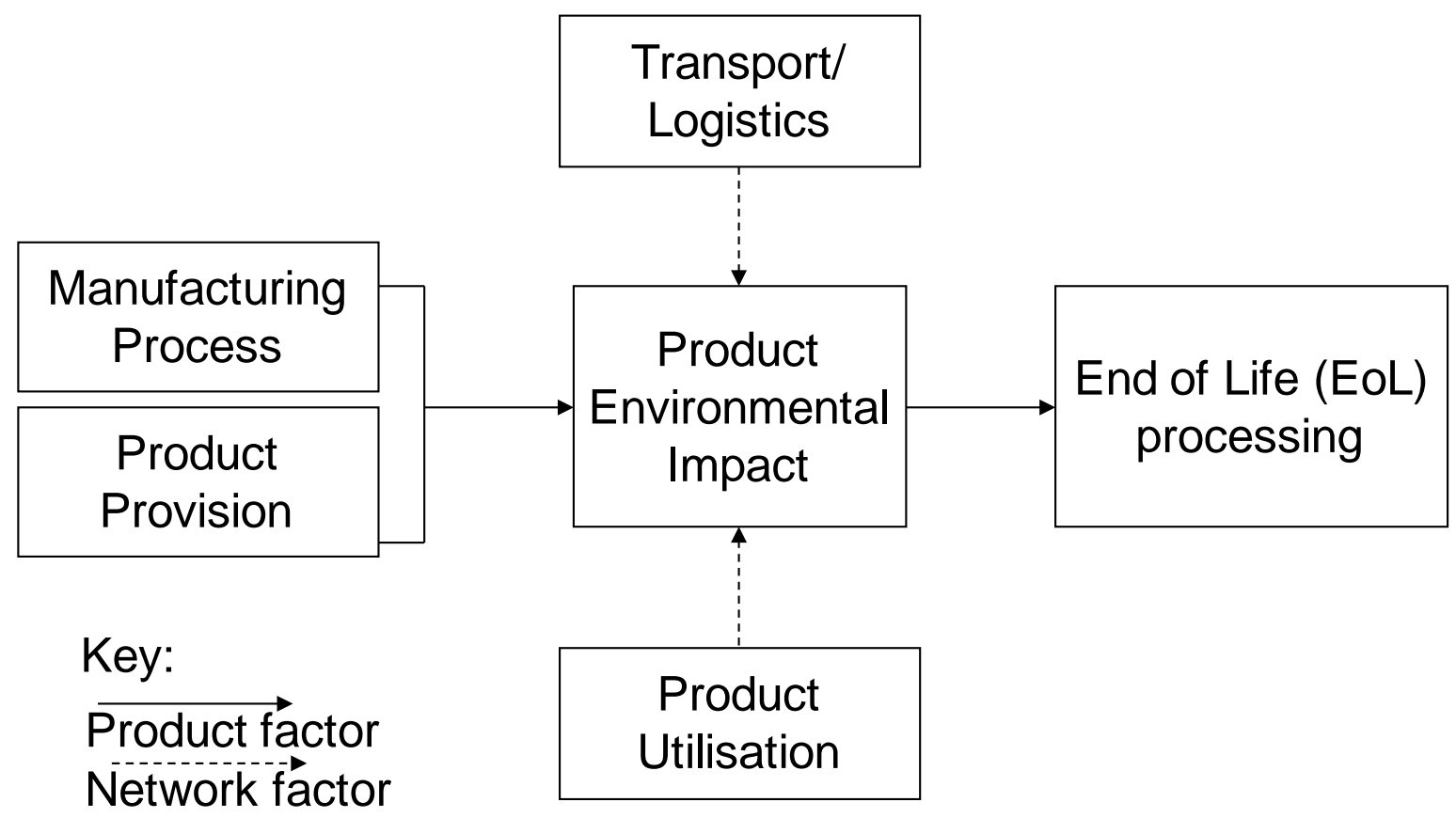

Figure 1. Scope of sustainable product development strategies.

The approach being advocated here is to broaden beyond the approach of reviewing existing products and improving their environmental performance, for example, reducing the materials utilised in the product or its packaging. Although this has its merits this incremental approach is limited in that it is modifying an existing product and hence is limited in its scope. Cause-and-effect mechanisms relating to product sustainability are becoming more recognised but are not widely adopted in terms of design practice of manufacturing firms. 


\section{SUSTAINABLE DEVELOPMENT STRATEGIES}

Approaches which support sustainability in two aspects are proposed, firstly, the provision of products to users in ways which extend the product life and secondly, manufacturing approaches which reduce resource usage. This is summarised by the framework for sustainable development strategies shown in Figure 2 below.

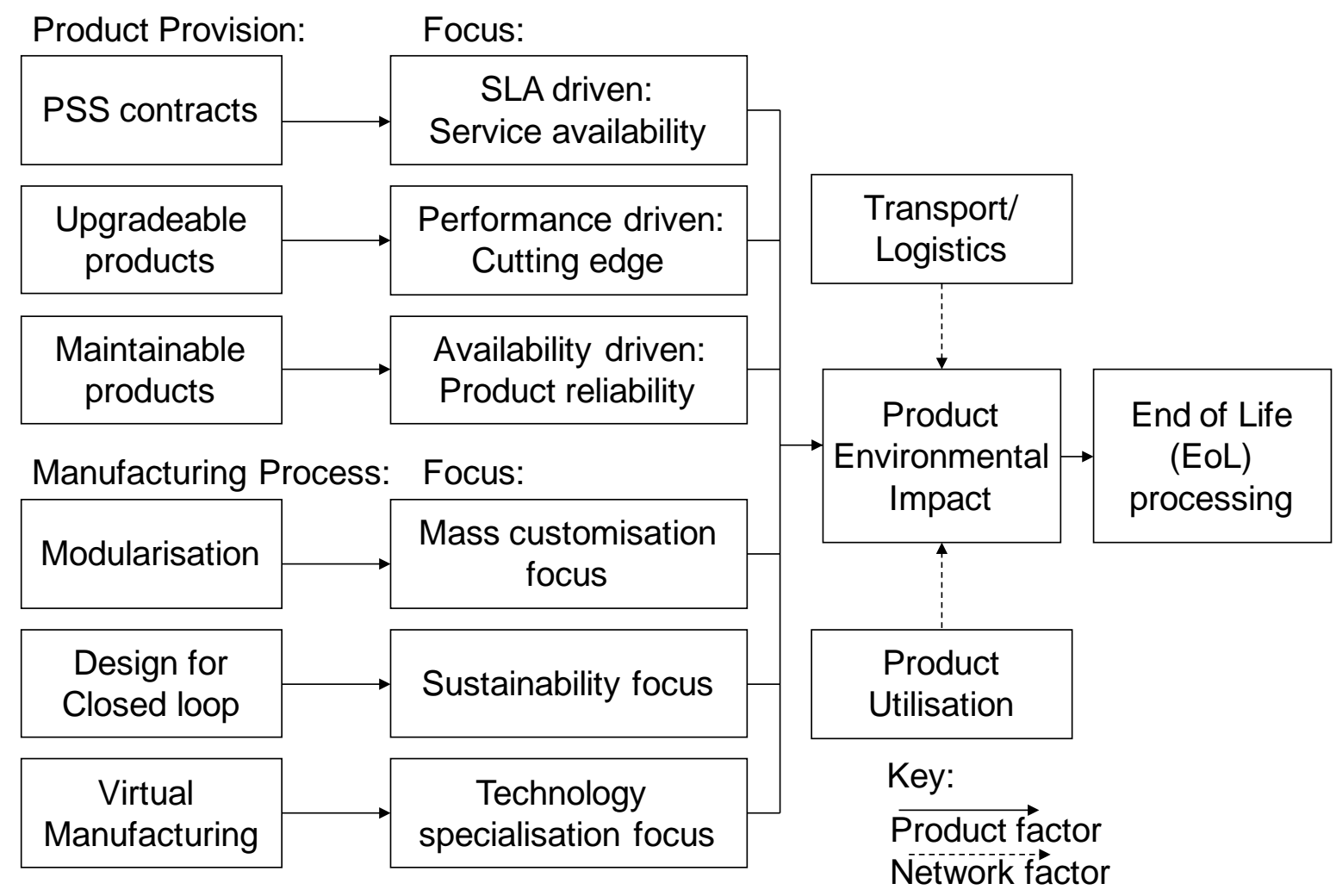

Figure 2. Sustainable development strategies

The framework identifies firstly, three strategies for product provision and secondly, three strategies for manufacturing process each having a different focus. In terms of the product strategies the focus is on service availability (where the product concept is altered to one of 
utility), then performance (upgrading to a higher specification graphics card in your computer for example) through to availability (such as for transport vehicles for example). Similarly, the manufacturing process strategies are focused on providing production approaches that achieve different outcomes.

This framework recognises that the manufacturing industry is being pressured from all sides to work towards sustainability, both in the design, operation and reuseability/disposability of their own products, but also in the manufacturing processes and machinery that they themselves use to manufacture their products. In the manner that the process of procurement has evolved into the concept of the supply chain - where every link affects and is affected by every other link both upstream and downstream - it is hardly surprising that similar modes of thinking about and describing sustainability in terms of 'chains' are beginning to appear. In the same manner as the concept of the supply chain has affected the way all companies do business, it is reasonable to suppose that these chain concepts of sustainability will have a similar impact. Thus the necessity for organisations to rethink their product and manufacturing process designs and rationales will become ever more important to success.

In terms of sustainable product development strategies three are reviewed in this paper which are a change to the widely used practice of consumers purchasing the products and using them for a period time that is relatively short before disposing of them rather than focusing on reducing the environmental impact and looking to extend the life of the product. In all three strategies for product provision there is a need to involve other parties 
who need to be suitably qualified and knowledgeable with the appropriate resources and organisational capability (Aurich [7]). Further, there needs to be ongoing sharing of information so that problems are resolved which may involve accessing knowledge and expertise from the other party.

In terms of manufacturing process focus, changes in manufacturing needs are being driven by (i) increasing customer 'sophistication' and expectations towards the provision of a wider variety of product choice, (ii) increasing visibility of green issues and the need to ensure security of raw materials and (iii) the increasing need for technology and associated technological expertise. Mass customisation is a solution to provide the required increased choice without the overheads of greater production facilities, the 'design for closed loop' approach may have the double benefit of forcing designers and manufacturers to think sustainably to preserve existing stocks and sources of raw materials and to design products specifically to encourage and facilitate the reuse of materials. The growing need for solutions which are based on technologies of increasing complexity and sophistication has already begun to influence the manner in which companies think about the 'ownership' of technological capabilities and is leading many organisations to conclude that the way forward is by partnership or 'buying-in' of the appropriate skills. In extreme cases this may well lead to even large organisations becoming more 'virtual' than 'real'.

Traditionally manufacturing has been focused on production quality and efficiencies rather than End of Life processing. The use of spot welding by robots has become common practice in large volume production operations such as in the automotive sector where 
considerable investment is made to automate the high capacity manufacturing. However, increasing emphasis on End of Life processing necessitates that both the materials and production processes are examined and changes made such that 'click and fit' approaches be adopted (where suitable) such as using lugs that can be easily undone which enables materials to be more easily retrieved and hence processed at the end of the vehicle's life.

It can be argued that the ICT industry has something of a lead on more traditional sectors of manufacturing. As an example, the touchscreen assembly of a typical laptop computer, generates its own unique set of problems when it comes to disposal, reuse or recycle. There are four existing display types: resistive, conductive, surface capacitance and projected capacitance, each of which has its own requirements for recycle. These types of screens can be difficult to differentiate between as they are not obviously different to the human eye often used in the recycle process and in particularly in the use of indium tin oxide (ITO) has properties which require the use of acids and other hazardous chemicals for extraction. New 'dry' processes have been developed recently to overcome these problems but many other issues particularly surrounding the use of rare or 'exotic' metals still remain to be solved for the safe recovery or disposal of electronic waste. 


\section{SUSTAINABLE MANUFACTURING PROCESS STRATEGIES}

Sustainability is broader in scope than making a more environmentally friendly product as it needs to encompass the whole lifecycle. A drive towards lower energy and resource usage (e.g. through lean manufacturing) is not necessarily the same as a sustainable approach simple reduction of energy and/or resources used in manufacture with no attempt to 'close the loop' will effectively only result in resources and energy taking longer to 'run out'. Exactly what sustainability is, is not clear and the problem of defining sustainability remains as highlighted by Scholtz and Tietje [8]. In fact Jacques et al [9] concluded that “... pointing out the reasons why products are not sustainable is typically easier than defining all the attributes that would make a product so...”.

\subsection{Re-configurable manufacturing}

Mass Customization (MC) is a strategy which aims to give organisations the abilities to meet the challenges inherent in producing a greater range of products but at the same time trying to keep the economies-of-scale benefits of mass production. Much work has been done (for example, Piller, [10]) on how to develop re-configurable manufacturing systems to enable mass customisation, often through use of methods designed to increase flexibility in manufacturing processes such as cellular manufacturing, flexible manufacturing systems (FMS), computer-controlled and reconfigurable machines, which when allied to internet or web-based technologies allow very close interaction with customers (often allowing the customer to become an integral part in the design process). 
Many early proponents of the mass customization approach like Davis [11], Pine [12] and Toffler [13] prophesied its adoption into general manufacturing with the advent of new manufacturing technologies like CIM and flexible manufacturing systems but recent research by Piller and Möslein, [14] based on 250 'mass customizing' companies suggests that to date the (successful) take-up has lagged behind these early predictions, largely due to a lack of appropriate technologies to handle the large amounts of information flows connected with mass customization and that new Internet based technologies will go some way to enable the successful implementation of mass customization in more and more consumer markets.

Although the initial driver of the mass customisation concept was as a reaction to the increasing desires of consumers for products which are 'different' or 'unique' (and therefore of higher perceived value) but without the associated higher costs of low volume manufacture, this quick adaptability to market demand, producing (in theory at least) only the correct amount of products (thereby reducing waste) and only when ordered by real customers should allow any organisation to make significant steps in the direction of sustainability.

To date, the most often applied solution to mass customised production is by careful and limited design of products so that customisation is based on variable assembly of similar but distinct parts - in terms of colour, finish, etc. for example kitchen unit worktops, doors or handles. This approach is designed so that the customisation of the product can be achieved with little disruption to the actual manufacturing process. However once the level of 
customisation reaches the point where the product is significantly different in terms of physical difference, e.g. the outer dimension of the case, then major issues in manufacture of variable design or configuration products appear. Reconfiguration of the manufacturing process can be achieved by use of inter-changeable tooling, jigs and fixtures, etc. or even development of reconfigurable tooling which can adapt its shape to fit a wider variety of needs. One example of such reconfigurable tooling from Wang et al [15] is a mould comprised of a number of pins which can be raised or lowered, all covered by a flexible rubber sheet to allow for the surface to be 'programmed' and quickly adapted for other shapes. Such reconfigurable tools are becoming more widespread in the aerospace industries.

One of the major problems for any manufacturing organisation is movement towards a goal of sustainability when that goal is difficult to define. What and where is the sustainability? Increasingly manufacturers talk of producing 'sustainable' products as their route to sustainable manufacturing however both products and their manufacturing processes need to be sustainable for any approach to be called truly sustainable. For example the use of timber source from sustainable sources (e.g. bearing the Forest Stewardship Council (FSC) mark) may be used to promote the 'green credentials' of a company but the equipment, methods and processes used to manufacture the products may have remained unchanged for decades. 


\subsection{Design for closed loop}

A number of concepts and ideas for sustainability have been developed like green design for manufacturing, design for the environment (DFE) or environmentally conscious design and manufacturing, which attempt to consider all environmental aspects of the materials, products operations and processes with the intention that they can be considered at the very earliest stages of design and manufacture.

Design for Recycling (DFR) uses processes from the natural world to conceptualise recycling activities. For example, the 'biological' cycle - where organic materials naturally degrade into new 'soil' to allow the growth and development of new life (product which function for their life and then can be safely discarded) and the 'industrial' cycle in which the materials in the product are recycled and reused continuously (as in the recycling of aluminium drinks cans reducing production costs by $60-70 \%$ and pollution by up to $90 \%$ ).

Cradle to cradle (C2C) is a term coined in the 1970s and has been developed by a number of researchers since McDonough [16] and considers the impact of each stage from mining of raw materials through to recycling, paying particular emphasis on:

- sustainable and efficient manufacturing using clean technologies;

- waste free production;

- use of non-hazardous and recyclable materials;

- reducing energy consumption;

- renewable energy sources;

- minimisation of environmental impact; 
- local sourcing of materials and energy;

- continuous review of the possibilities of reuse and recycling of materials.

Legislative drivers have been shown to be an important driver in terms of improving manufacturing sustainability and it's likely that all manufacturing machine tools will probably require $\mathrm{A} / \mathrm{B} / \mathrm{C} / \mathrm{etc}$. energy efficiency labelling of the type currently required for domestic 'white' goods like washing machines, refrigerators or tumble dryers as shown in Figure 3.

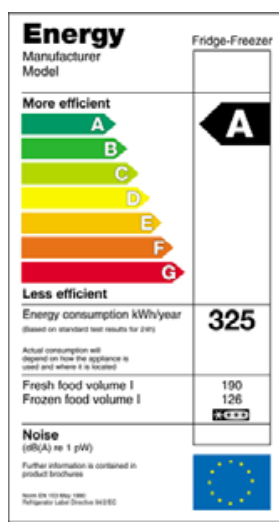

Figure 3. Example of domestic white goods energy labelling

An outcome of such legislation is that it will lead to the energy efficiency criteria becoming an important factor in decisions to purchase, repair or remanufacture equipment purchased by manufacturing companies (once the technical capabilities of the machine has been satisfied). One of the major problems with adoption of these types of sustainability 'philosophies' will undoubtedly the costs associated with modifications of existing raw materials selection, manufacturing methods and processes. Given the recent history of struggles to change attitudes in most industries (e.g. reduction in sulphur content of fuels to 
combat acid rain in the 1970's) it seems likely that unless any changes to be made can be unequivocally demonstrated to be of real economic benefit to the industry then any steps forward will need to be driven by legislation. A good example of such legislation driving change cited by Livingston and Sparks [17] happened in the 1990s where changes to German packaging law which required the use of high levels recycled materials drove the industry to adapt and become more sustainable. 


\section{SUSTAINABLE PRODUCT DEVELOPMENT STRATEGIES}

Different sustainable development strategies are required for different types of products which entails that sustainable strategies need to target specific sectors as argued by Hanssen, [18]. The telecoms sector is a global sector, for example, where consumers are using increasingly integrated handheld devices for purposes of connectivity and various other applications. Strategies for this sector will need to recognise the competitive pressures as well as consumer pressures to make the latest applications available and the best product capabilities.

The first strategy for product provision is where equipment is leased rather than purchased either by service providers or end users. This approach is known as Product-Service Systems (PSS) and the focus is service availability for the user. The second strategy for product provision is one where the focus is on high performance products and this is achieved by providing products which are upgradeable. In contrast, the third strategy for product provision is on products where their availability is of paramount importance and hence product reliability is the major concern to the user and this is achieved by providing

products which are maintainable. Although this may seem "obvious" consider many consumer devices where this is not the case, for example, the majority of the UK population own and carry a mobile phone however few of us are able to keep it maintained or get it repaired when part of it becomes damaged and it is environmentally wasteful to have to replace an entire mobile phone handset when the screen becomes damaged due to user wear and tear. 


\subsection{PSS contracts}

At a generic level a manufacturing firm supplying equipment for product-service system applications will be incurring costs in order to provide the necessary pre and post sales functions for the product-service system activities. The main cost elements identified by De Coster [19] comprise: capital investment; manufacturing activities; logistics activities and customer lifecycle support.

The additional expenditure on services for the provision of product-service system applications has the benefit that manufacturing firms will be working more closely with their end users and hence, get greater insights to their needs. This can become the basis for competitive advantage as markets become global companies look to differentiate themselves from their competitors (to avoid losing market share or having to reduce prices and hence, margins. This shows that it is hard to compare the "costs" involved as other benefits may be realised which are less tangible and hard to quantify.

The barriers to product-service systems that have been recognised in the extant literature relate to relationships amongst the different parties in the value chain (Mont [20]). Establishing business relationships with external partners is increasingly necessary to meet market requirements; however, business processes are context dependent (Gilbert and Cordey-Hayes [21]) which makes it more challenging to provide PSS applications using business partnerships. The level of interaction amongst the parties involved does vary as product-service systems are of different types (Tukker [22]) so whether this issue is a barrier or not will depend on the product concerned. 


\subsection{Upgradeable products}

The cost implications are less for the second and third strategies for product provision and for the manufacturer focus around the need to redefine subsystems as functional or structural modules and specify its interfaces. Arguably these approaches are more likely to be acceptable to both manufactures and consumers for who ownership of a product is the normal form of business transaction.

The complexity of protocols, standards and interfaces which are prevalent in the high technology sectors (such as mobile phones for example), means that customers are themselves often uncertain on the most appropriate applications/technologies to adopt for their application. The manufacturing companies need to have a clear view "to the protocol/method”, on the interoperability aspects when proposing applications/technologies that provide customers with upgrade and new applications or system solutions.

The key benefit for a manufacturing company that utilises their legacy products and market experience to offer product upgrades is that they already have established a market presence. This is necessary to gain credibility with other firms that they deal with including supply chain partners and financiers i.e. the benefit is not only limited to customer acceptance but also other firms in that sector. Further, they have a reduced risk in terms of engineering the required product upgrades as they will already possess part of the required product functionality and necessary technological skills. 


\subsection{Maintainable products}

The third strategy (of maintainable products) also has product development implications for manufacturers as it necessitates that they examine a product and allow for the need for repair which may involve (to some extent) disassembly. Product redesign is normally required for disassembly (Jones [23]) so that difficult jobs such as instrument panel removal can be made much simpler, cutting service time. This requirement also applies to productservice systems where maintenance has now become the responsibility of the manufacturer (e.g. aircraft maintenance) who will now have the incentive to design easy access to key systems.

In some sectors the need for maintenance to ensure ongoing operational parameters is an established part of the product specification. Procurement of equipment will address the technical and related aspects of maintenance such as equipment configuration and ease of access for maintenance personnel. Sectors where equipment is costly and is required for operational use over a period of time that is years in length will be familiar with the need for

field operators to provide repairs and upgrades, however, this is not widespread amongst other high technology sectors. 


\section{EVALUATION OF SUSTAINABLE STRATEGIES}

Convincing manufacturing firms to adopt or even consider for adoption these sustainable product development strategies will require an examination of the implications to the business case particularly the cost aspect. For PSS strategies the defining of deliverables and the parties responsible during contract negotiations will have an impact on the cost benefit analysis. Thus, a generic cost model for PSS firms is not very useful as the costs involved are not only sector dependent but also very context dependent as it depends on the contractual deliverables. Notwithstanding this a framework is shown in Figure 4 which will be used to examine the cost elements for each of the sustainable product development strategies.

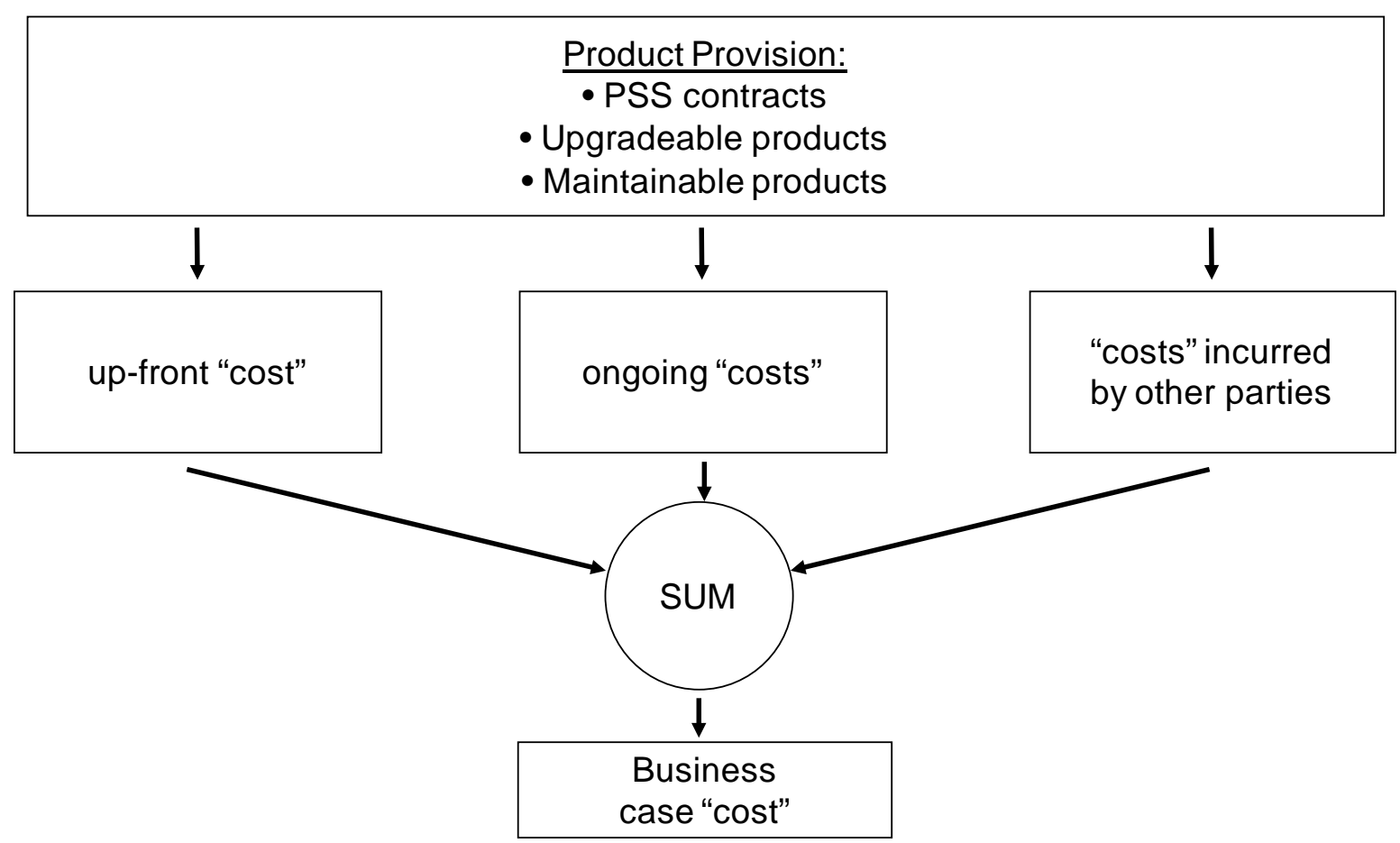

Figure 4. Cost elements of sustainable product development strategies 
Three cost elements are identified in Figure 4 which represent three stages of the life-cycle from the viewpoint of a manufacturer: the up-front "cost"; the ongoing "costs" and the “costs" incurred by other parties. The telecoms sector is a global sector characterised by high volumes and rapid technological advances. Here we consider the example of mobile handsets which are used by people to provide communications; entertainment; corporate and other applications. There are an increasing number of mobile user devices which need to be supported - both for industrial purposes and for consumer electronics. There has been a gradually evolving range of mobile devices which is extending as different groups of users see the benefits of wireless connectivity, for example, healthcare for home patient monitoring.

A major part of the up-front "cost" is at the design and development stage. The design aspects for each device, service and application need to address the service concept aspects and the mobile user interface design to ensure usability. The growth in diversity of mobile devices is yet to occur and includes Smartphones, PDAs, Portable Media Centers, retail point-of-sale systems, Global Positioning System-based devices and industrial robots. This increasing number of user devices are challenging to support as they each have different interface requirements. 


\subsection{Business planning and costing implications}

The business measures affected by these sustainable strategies are examined drawing on product development case studies from a number of high technology sectors to highlight the different approaches taken. Specific “cost” items within these elements are illustrated in Table 1; they include training and deployment of field service personnel by the vendor to support ongoing field operations at remote sites.

\begin{tabular}{|c|c|}
\hline & Business case “cost” items \\
\hline $\begin{array}{l}\text { Up-front } \\
\text { “cost” }\end{array}$ & $\begin{array}{l}\text { - Requirements capture and PSS development costs } \\
\text { - Testing and validation of product features and user applications } \\
\text { - Field deployment of the equipment which has been leased } \\
\text { - Training of field personnel who will be based remotely }\end{array}$ \\
\hline $\begin{array}{l}\text { Ongoing } \\
\text { “costs" }\end{array}$ & $\begin{array}{l}\text { - Technical support to aid integration and equipment utilisation } \\
\text { - Field support of the equipment which has been leased (upgrades) } \\
\text { - Servicing and repairs of the equipment as needed (or contracted) }\end{array}$ \\
\hline $\begin{array}{l}\text { "costs" } \\
\text { incurred by } \\
\text { other parties }\end{array}$ & $\begin{array}{l}\text { - Interfacing with the vendor during PSS development phase } \\
\text { - Offices / engineering space to accommodate service personnel } \\
\text { - Management of Service Level Agreements (SLAs) }\end{array}$ \\
\hline
\end{tabular}

Table 1. Business case items for PSS goods and services

A manufacturing firm supplying equipment for PSS applications will be incurring costs in order to provide the necessary pre and post sales functions for the PSS activities. The business case items illustrated in Table 1 highlights that a key aspect that affects the business case is the need for vendor sourced personnel to be located remotely to support 
ongoing operations. Identifying costs based on the resource requirements for co-located PSS must also recognise the need to support or to interface to these operational integration aspects argues De Coster [19].

The support activities for PSS during the user phase are carried out by specialists in different functions and this requires coordination across the various functions for successful service delivery. To obtain visibility of the various activities it is necessary to develop business processes and information systems to make information retrieval both fast and sufficiently accurate. Essentially there is a cost to ensure that PSS operations interface to corporate information systems to ensure the smooth flow of business operations. The cost elements identified which represent three stages of the life-cycle from the viewpoint of a manufacturer are now examined in Table 2 . 


\begin{tabular}{|c|c|c|c|}
\hline $\begin{array}{l}\text { Product } \\
\text { Provision: }\end{array}$ & Up-front "cost" & Ongoing “costs" & $\begin{array}{l}\text { "Costs" incurred by } \\
\text { other parties }\end{array}$ \\
\hline PSS contracts & $\begin{array}{l}\text { Capital investment } \\
\text { Manufacturing } \\
\text { activities }\end{array}$ & $\begin{array}{l}\text { Logistics activities } \\
\text { Customer lifecycle } \\
\text { support }\end{array}$ & $\begin{array}{l}\text { Specification of the } \\
\text { SLA } \\
\text { Management of the } \\
\text { SLA during the } \\
\text { contract period }\end{array}$ \\
\hline $\begin{array}{l}\text { Upgradeable } \\
\text { products }\end{array}$ & $\begin{array}{l}\text { Technical data } \\
\text { provision } \\
\text { Interface }\end{array}$ & $\begin{array}{l}\text { Platform solutions } \\
\text { Managing product } \\
\text { releases }\end{array}$ & $\begin{array}{l}\text { Upgrade execution } \\
\text { Problem resolution } \\
\text { Payment handling }\end{array}$ \\
\hline $\begin{array}{l}\text { Maintainable } \\
\text { products }\end{array}$ & $\begin{array}{l}\text { Subsystem scope } \\
\text { Functionality of } \\
\text { subsystems }\end{array}$ & $\begin{array}{l}\text { Integration of the } \\
\text { subsystems } \\
\text { Provision of technical } \\
\text { information }\end{array}$ & $\begin{array}{l}\text { Sourcing parts } \\
\text { Servicing } \\
\text { Problem resolution } \\
\text { Factory interface } \\
\text { Payment handling }\end{array}$ \\
\hline
\end{tabular}

Table 2. Cost implications of sustainable product development strategies.

In all three strategies for product provision there is a need to involve other parties who need to be suitably qualified and knowledgeable with the appropriate resources and organisational capability (Aurich [7]). Further, there needs to be ongoing sharing of 
information so that problems are resolved which may involve accessing knowledge and expertise from the other party.

Changes in operating models are ones which may lead to the greatest potential for improving sustainability such as the emerging trend in the ICT sector towards Cloud Computing. Currently organisations provide the majority of their ICT infrastructure themselves which involves investment and the running of high capacity data processing and storage solutions. A move towards Cloud Computing where organisations access specific IT services/applications through a central provider such as Google Maps for example, is an approach which has the potential to reduce carbon emissions significantly. Further, remote and consolidated server farms will lead to economies of scale that result in reduced power requirements and carbon emissions and hence improvements in sustainability.

Arguably there is a need to shift the thinking of business executives away from the existing appraisal methods for assessing the "value" of equipment towards one that is more holistic and encompasses environmental impacts and the overall issues of sustainability. Executives decisions in terms of ICT solutions are often based on technical and performance aspects as they do not want their network performance degraded. Network integration is a complex issue particularly for organisations where workers are not co-located and hence investments in networking equipment must account for geographic separation and the entailing integration and support needs. 


\subsection{Measures to evaluate sustainability}

Lifecycle analysis is well recognised as a mechanism that can aid during the development stage of the design process as it enables assessment of environmental performance as highlighted by Maxwell et al [24]. Lifecycle analysis is advocated by Miettinen and Hämäläinen [25] as it enables quantification of product specifications so that alternate designs can be assessed in terms of the ecological impact by characterising product attributes and key elements. The breadth of the analysis is that three main life cycle aspects are considered as identified by Schmidt and Butt [6]: production of the product; the user phase and the end of life environmental costs. This highlights that manufacturing firm's need to consider sustainability measures and impacts as part of their Innovation strategy which is a part of a firm's overall strategy and develops strategies for managing technology and innovation as identified by Cooper [26].

Measuring the carbon footprint has been an approach that is widely used and has the advantage in that it provides a measure that can be used to make comparisons either amongst manufacturing firms or historical trends. However, evaluation of sustainable strategies needs to focus on specific aspects of the production of goods and their handling over the lifecycle. This will range from decisions made at the product design stage such as the use of lighter materials for example, composites that may provide a weight reduction. However, in contrast these composite materials are more difficult to process at EoL processing. Thus, we also need elements that assess the percentage of materials that are 
discarded at EoL processing which will affect manufacturing techniques that support product EoL processing such as the use of fasteners rather than glue to join parts together. Table 3 identifies some of the elements that can be used to evaluate the level of sustainability of different product provision and manufacturing strategies.

\begin{tabular}{|l|l|}
\hline & Evaluation elements to address sustainability \\
\hline Product & - Materials reduction: product/ packaging materials used \\
& - Materials selection: bio degradable or re-cycled materials \\
- Lighter materials: weight reduction \\
- Packaging: bio degradable or re-cycled materials \\
- Support for re-engineering: labelling parts \\
- EoL: amount of parts that need to be disposed \\
\hline Manufacturing & - Process efficiencies: resource and energy reduction \\
Process & - By products: pollution and waste minimisation \\
& - Accessibility for product servicing / repairs \\
& - Techniques that support product EoL processing \\
\hline
\end{tabular}

\section{Table 3. Evaluation of sustainable strategies}

Consumer acceptance of PSS goods and services is not well researched or documented in the extent literature. Traditional marketing techniques for assessing consumer reactions are based on the premise that products are purchased and used by the owners of the equipment. Theories such as consumer acceptance of technology or diffusion theories which address 
adoption of new products or technologies by organisations are all based on the premise of product ownership rather than product leasing.

The revenue model for a manufacturing firm which is supplying equipment for PSS applications comprises three generic revenue sources as identified by De Coster [19]: PSS contracts; Product sales and Bespoke (or custom development) of products or consulting services. Forecasts will need to be established for each of these three generic revenue sources which requires good insights into the service aspects that matter to customers which entails a close working relationship that can best be realised when a vendor has a service team co-located with the customer.

Forecasting methods for products and separately for services are well documented in the extant literature, however, the literature concerning forecasting for PSS is not yet well established. The difficulty with a move to PSS is that the timescales in which the forecasts can be proved to be valid are lengthy which prevents using historic data as a basis for developing predictions on take-up of services of this nature.. 


\section{CONCLUSIONS AND FURTHER RESEARCH}

The environmental pressures on manufacturers are increasing and they are under pressure to make changes, however, they have a legacy infrastructure which needs to be accommodated in any sustainability strategies. This paper contributes by proposing methods and models to examine opportunities for improving the environmental impact of products within the constraints of existing manufacturing infrastructure.

This paper reviews three sustainable product development strategies and examines the business planning and cost implications. Both manufacturing processes as well as the products produced need to be considered for sustainable manufacturing and strategies for both of these were proposed and examined leading to the development of a framework. These were examined in terms of the manufacturing and consumption of goods from the perspective that sustainability needs to be optimised in a "closed loop" manner. These findings highlight the need for sustainability metrics which is an area which we are actively researching.

\section{ACKNOWLEDGEMENTS}

This material is a development on previous research presented in a conference paper at the 15th Annual Cambridge International Manufacturing Management Symposium on "Innovation in global manufacturing - new models for sustainable value capture", held September, 2010 at Cambridge University, UK. 


\section{REFERENCES}

1. Van Weenen JC. Towards sustainable product development. Journal of Cleaner Production 1995; 3/1-2: 95-100.

2. Donnelly K, Olds R, Blechinger F, Reynolds, D. and Beckett-Furnell Z. ISO 14001 effective management of sustainable design. The Journal of Sustainable Product Design 2004; 4: 43-54.

3. Ljungberg LY. Materials selection and design for development of sustainable products. Materials \& Design 2007; 28: 466-470.

4. Mann D and Jones E. Sustainable services \& systems (3s) through systematic innovation methods. The Journal of Sustainable Product Design 2002: 2: 131-139.

5. van Nes N and Cramer J. Design strategies for the lifetime optimisation of products, The Journal of Sustainable Product Design 2003; 3: 101-107.

6. Schmidt WP, Butt F. Life Cycle Tools within Ford of Europe's Product Sustainability Index. Case Study Ford S-MAX \& Ford Galaxy, The International Journal of Life Cycle Assessment 200; 11/5: 315-322.

7. Aurich JC, Mannweiler C and Schweitzer E. How to design and offer services successfully. CIRP Journal of Manufacturing 2010; 2: 136-14.

8. Scholtz RW and Tietje O. Embedded case study methods: integrating quantitative and qualitative knowledge, Thousand Oaks, Calif. USA. Sage Publications, 2002.

9. Jacques JJ, Agogino AM and Guimaraes LBM. Sustainable Product development initiatives in the footwear industry based on the cradle to cradle concept, Proceedings of the ASME 2010 International Design Engineering Technical Conferences \& Computers 
and Information in Engineering Conference, IDET/CIE 2010, August 15-18 2010, Montreal, Quebec, Canada.

10. Piller F. Mass Customization, Wiesbaden, Gabler Davis, 2001.

11. Davis S. Future Perfect, Addison-Wesley, Reading, UK, 1987.

12. Pine BJ. Mass Customization - The New Frontier in Business Competition, Boston, MA, Harvard Business School Press, USA, 1993.

13. Toffler A. Future Shock, Orbit Publishing, Cologny, Geneva, CH, 1970.

14. Piller FT and Möslein K. From economies of scale towards economies of customer integration: value creation in mass customization based electronic commerce, in Working Paper No. 31 of the Department of General and Industrial Management, Technische Universität München, 2002, 8/2002.

15. Wang Z, Gindy N, Tang R and Gu XJ. Automated discrete-pin adjustment for reconfigurable moulding machine, International Journal of Computer Integrated Manufacturing, 2010; 23/3, 229-236.

16. McDonough W and Braungart M. Cradle to cradle: remaking the way we make things, North Point Press NY, USA, 2002.

17. Livingstone S and Sparks L. The New German Packaging Laws: Effects on Firms Exporting to Germany. International Journal of Physical Distribution \& Logistics Management, 1994, 24/7, 15 - 25.

18. Hanssen OJ. Sustainable product systems--experiences based on case projects in sustainable product development. Journal of Cleaner Production 1999; 7: 27-41. 
19. De Coster R. A collaborative approach to forecasting product-service systems (PSS). The International Journal of Advanced Manufacturing Technology 2011; 52: 9, 12511260.

20. Mont O. Drivers and barriers for shifting towards more service-oriented businesses: Analysis of the PSS field and contributions from Sweden. The Journal of Sustainable Product Design 2002; 2: 89-103.

21. Gilbert M and Cordey-Hayes M. Understanding the process of knowledge transfer to achieve successful technological innovation. Technovation 1996; 16 (6): 301-315.

22. Tukker A. The potential of $\mathrm{CO} 2$ reduction from household consumption by productservice systems - A reflection from SuSProNet. The Journal of Sustainable Product Design 2006; 3: 109-118.

23. Jones N, Harrison D, Hussein H, Billett E and Chiodo J. Towards selfdisassembling vehicles. The Journal of Sustainable Product Design 2003; 3: 59-74.

24. Maxwell D, Sheate W and van der Vorst R. Functional and systems aspects of the sustainable product and service development approach for industry, Journal of Cleaner Production 2006; 14: 1466-1479.

25. Miettinen P. and Hämäläinen RP. How to benefit from decision analysis in environmental life cycle assessment (LCA), European Journal of operational research 1997; 102: 279-294.

26. Cooper RG. Product innovation and technology strategy. Research Technology Management 2000; 43/1: 38-41. 